\title{
Opposing Roles of Cholinergic and GABAergic Activity in the Insular Cortex and Nucleus Basalis Magnocellularis during Novel Recognition and Familiar Taste Memory Retrieval
}

\author{
Gabriela Rodríguez-García and María Isabel Miranda \\ Departamento de Neurobiología Conductual y Cognitiva, Instituto de Neurobiología, Universidad Nacional Autónoma de México, 76230 Querétaro, México
}

Acetylcholine (ACh) is thought to facilitate cortical plasticity during memory formation and its release is regulated by the nucleus basalis magnocellularis (NBM). Questions remain regarding which neuronal circuits and neurotransmitters trigger activation or suppression of cortical cholinergic activity. During novel, but not familiar, taste consumption, there is a significant increase in ACh release in the insular cortex (IC), a highly relevant structure for taste learning. Here, we evaluate how GABA inhibition modulates cholinergic transmission and its involvement during taste novelty processing and familiar taste memory retrieval. Using saccharin as a taste stimulus in a taste preference paradigm, we examined the effects of injecting the $\mathrm{GABA}_{\mathrm{A}}$ receptor agonist muscimol or the $\mathrm{GABA}_{\mathrm{A}}$ receptor antagonist bicuculline into the IC or NBM during learning or retrieval of an appetitive taste memory on taste preference in male Sprague Dawley rats. $\mathrm{GABA}_{\mathrm{A}}$ receptor agonism and antagonism had opposite effects on cortical ACh levels in novel taste presentation versus familiar taste recognition and ACh levels were associated with the propensity to acquire or retrieve a taste memory. These results indicate that the pattern of cortical cholinergic and GABAergic neuroactivity during novel taste exposure is the opposite of that which occurs during familiar taste recognition and these differing neurotransmitter system states may enable different behavioral consequences. Divergences in ACh and GABA levels may produce differential alterations in excitatory and inhibitory neural processes within the cortex during acquisition and retrieval.

Key words: appetitive; GABA receptors; microdialysis; pharmacology; taste preference

\section{Significance Statement}

During learning and recall, several brain structures act together. This work demonstrates interactions between cortical cholinergic and GABAergic systems during taste learning and memory retrieval. We found that the neuroactivity pattern during novel taste exposure is opposite that which occurs during familiar taste recognition. $\mathrm{GABA}_{\mathrm{A}}$ receptors must be inactive during novel tasting to enable new memory formation, but must be active and inhibiting acetylcholine release in the cortex to allow memory retrieval. These findings indicate that GABA inhibition modulates cholinergic transmission and that cholinergic-GABAergic system interactions are important during the transition from novel to familiar memory.

\section{Introduction}

Cholinergic neurotransmission in the brain plays a critical role in attention, learning, and memory (Decker and McGaugh, 1991;

\footnotetext{
Received June 18, 2015; revised Dec. 18, 2015; accepted Dec. 21, 2015.

Author contributions: M.I.M. designed research; G.R.-G. performed research; G.R.-G. and M.I.M. analyzed data; G.R.-G. and M.I.M. wrote the paper.

This work was performed in partial fulfillment of the requirements to obtain a doctorate degree (Doctorado en Ciencias Biomédicas) from the Instituto de Neurobiología of the Universidad Nacional Autónoma de México (UNAM), by G.R.-G., who received a graduate scholarship 267860 from CONACYT (Grants CONACYT 152208, PAPIIT IN220991, and PAPIIT IN204615). We thank Angela Gabriela Vera-Rivera, José Alejandro Rangel-Hernández, Leonor Casanova, and Lourdes Lara for technical support and Shaun Harris, Ann Power, and Michael Jeziorski for English edition review.

The authors declare no competing financial interests.

Correspondence should be addressed to María-Isabel Miranda, UNAM-Campus Juriquilla, Boulevard Juriquilla №.3001, 76230 Juriquilla Querétaro, México. E-mail: mirandami@unam.mx.
}

Everitt and Robbins, 1997; Sarter and Bruno, 1997) and has a widespread modulatory function over other neurotransmitters (Decker and McGaugh, 1991; Giovannini et al., 1998; Ceccarelli et al., 1999; Miranda and Bermúdez-Rattoni, 1999; Giovannini et al., 2001). Acetylcholine (ACh) appears to be particularly important for the encoding of novel experience memories (Inglis et al., 1994; Acquas et al., 1996; Weinberger and Bakin, 1998; Hasselmo and McGaughy, 2004; Douchamps et al., 2013). Indeed, cholinergic activation is used as a marker of novelty and the role of ACh in the detection of a novel taste is well documented (Berman et al., 2000; Miranda et al., 2000; Gutiérrez et al., 2003; Miranda et al., 2003). Taste memory is a representation, not only of the ex- 
plicit characteristics of a gustatory stimulus, but also of its degree of familiarity.

Accordingly, cortical activity during taste memory acquisition differs from that which occurs during memory retrieval, supporting the notion that ACh may facilitate cortical plasticity during memory formation. For example, during novel, but not familiar, taste consumption, there is a significant increase in $\mathrm{ACh}$ release in the insular cortex (IC), an important structure in taste learning (Gutiérrez et al., 2003; Bermúdez-Rattoni, 2004). This ACh release is controlled by the nucleus basalis magnocellularis (NBM) in the basal forebrain (Miranda and Bermúdez-Rattoni, 1999). The NBM provides most of the cholinergic and GABAergic inputs to the cortex and subserves attentional functions required in learning and memory processes (Casamenti et al., 1986; Decker and McGaugh, 1991; Hasselmo, 2006). However, questions remain regarding which neuronal circuits and neurotransmitters trigger and/or accompany the activation and suppression of cortical cholinergic activity during novel and familiar stimulus recognition, respectively.

Cortical GABA release is increased during exploration of familiar, but not novel, environments (Giovannini et al., 2001). GABA may modulate cholinergic activity through interaction with GABAergic cortical interneurons or GABAergic inputs from the NBM (Wood and Richard, 1982; Záborszky et al., 1986) or via GABA receptors in the NBM itself (Chu et al., 1990; DeSousa et al., 1994). Injection of GABA or the $\mathrm{GABA}_{\mathrm{A}}$ receptor agonist muscimol into the NBM has been shown to impair memory formation in several paradigms (Majchrzak et al., 1990; Dudchenko and Sarter, 1991; Muir et al., 1992) and to decrease cortical ACh release (Casamenti et al., 1986). Cholinergic terminals in the IC are GABA-ceptive, receiving inputs from GABAergic interneurons (Ogawa et al., 1998), suggesting that cholinergic inputs to the IC are also inhibited by GABA inputs from the NBM.

In the present study, we examined how GABA inhibition modulates cholinergic transmission and its involvement in learning and retrieval. We evaluated cholinergic-GABAergic interactions between the NBM and IC during novel taste memory formation and familiar taste memory retrieval over $4 \mathrm{~d}$ of taste preference trials. First, we evaluated whether activation of $\mathrm{GABA}_{\mathrm{A}}$ receptors in the NBM and IC with the $\mathrm{GABA}_{\mathrm{A}}$ receptor agonist muscimol or inhibition with the $\mathrm{GABA}_{\mathrm{A}}$ receptor antagonist bicuculline affects the formation and/or retrieval of taste preference memory. Second, we used microdialysis in freely moving rats to examine the effects of activation or inhibition of $\mathrm{GABA}_{\mathrm{A}}$ receptors in the NBM and IC on cortical release of ACh and GABA during novel and familiar taste consumption trials. The justification for our experimental protocol was based on the major finding that a single session of drinking a novel tastant elicits long-term taste memory (Bures et al., 1998; NúñezJaramillo et al., 2010). This long-term memory is manifested as a taste preference (i.e., appetitive memory) and can be measured by the significant increments in consumption from day to day; therefore, we used the consumption values of saccharin solution compared with water as on indication of stored taste memory.

\section{Materials and Methods}

Rats. A total of 230 male Sprague Dawley rats (250-300 g) were used. They were placed in individual acrylic cages and maintained at $23^{\circ} \mathrm{C}$ on an inverted $12 \mathrm{~h} / 12 \mathrm{~h}$ dark/light cycle; all behavioral protocols were implemented during the dark phase. Food and water were available ad libitum until the behavioral procedures began. The experiments were performed in accordance with the Mexican Laws for Animal Care (Norma Oficial Mexicana SAGARPA) and the relevant rules set forth by the Mexican Ministry of Health. The experimental protocol was approved by our institutional Animal Care Committee (Comité de Bioética del Instituto de Neurobiología de la UNAM) and confirmed to be in compliance with the National Institutes of Health's Guidelines for the Care and Use of Laboratory Rats (NIH publication 80-23, revised 1996).

Surgery. Rats were anesthetized with intraperitoneal injections of ketamine $(70 \mathrm{mg} / \mathrm{kg})$ and xylazine $(6 \mathrm{mg} / \mathrm{kg})$ and submitted to standard stereotaxic procedures after one of the five surgical cohorts: (1) bilateral IC injection using two 23-gauge stainless steel cannulae; (2) bilateral NBM injection using two 23-gauge stainless steel cannulae; (3) bilateral IC injection using a 23-gauge stainless steel cannula in the left IC and a microdialysis guide cannula with an injection tube (BASi MD 2262) in the right IC (Fig. 1A); (4) bilateral NBM injection using two stainless steel cannulae and a microdialysis probe cannula (BASi MD 2204) in the right IC (Fig. $1 B$ ); or (5) unilateral right IC microdialysis probe cannula CXG-12 (Eicom 807.10) for GABA determination. The stereotaxic coordinates used to target the IC (Paxinos and Watson, 1998) were $1.2 \mathrm{~mm}$ anterior and $5.5 \mathrm{~mm}$ lateral to bregma, with injection guide cannulae being lowered to $3.0 \mathrm{~mm}$ ventral of the skull surface $(2.0 \mathrm{~mm}$ above the IC) and microdialysis guide cannulae being lowered to $4.5 \mathrm{~mm}$ ventral of the dura $(0.5 \mathrm{~mm}$ above the IC). The stereotaxic coordinates used to target the NBM were $1.5 \mathrm{~mm}$ posterior and $2.5 \mathrm{~mm}$ lateral to bregma, with injection guide cannulae being lowered to $4.9 \mathrm{~mm}$ ventral of the skull surface $(2.5 \mathrm{~mm}$ above the NBM). The injection cannulae and microdialysis guide cannulae were fixed to the skull with two surgical screws and dental acrylic cement. Stylets were inserted into the guide cannulae to prevent clogging.

Taste preference protocol. Five days after surgery, once they had recovered completely, the rats were water deprived for $20 \mathrm{~h}$ and then habituated once a day to drinking water from two graduated bottles for $15 \mathrm{~min}$ over $4 \mathrm{~d}$ to measure stable baseline water consumption. The two bottles filled with water were placed on opposite sides of the home cage lid and, during every presentation day, were switched every 2 min to avoid consumption from a single bottle. On day 5 , the taste preference trial (SAC1) was initiated, wherein the rats had access to one bottle filled with water and another filled with a novel taste solution ( $0.1 \%$ saccharin) placed on opposite sides of the home cage lid and switched every $2 \mathrm{~min}$. During the 3 subsequent days, the rats were again presented with water and saccharin solution bottles and the development of a taste preference was evaluated (SAC2-SAC4). Saccharin consumption was quantified as the percentage of fluid consumed per day as follows: $\%$ saccharin consumption $=($ saccharin $\mathrm{ml} \times 100) /($ saccharin $\mathrm{ml}+$ water $\mathrm{ml})$.

Drug injections. Independent groups were used for novel (SAC1) versus familiar (SAC3) drug manipulation days and for each agonist or antagonist injection in the IC or in the NBM. For microinjections, patency stylets were removed and 30-gauge injection needles were inserted into the stainless steel cannulae. The injection needles protruded 2.5 and $2.0 \mathrm{~mm}$ beyond the cannulae for the NBM and insular cortex, respectively. The injectors were connected via polyethylene tubing to $10 \mu \mathrm{l}$ microsyringes driven by an injection pump (Carnegie Medicine). In accordance with their group designations, rats received bilateral microinjections of $0.9 \%$ saline solution $(0.5 \mu \mathrm{l}$; control group), muscimol $(0.07$ $\mu \mathrm{g} / 0.5 \mu \mathrm{l}$; Sigma-Aldrich), or bicuculline $(0.07 \mu \mathrm{g} / 0.5 \mu \mathrm{l}$; Tocris Bioscience) into the NBM or IC. Other independent groups were used for microdialysis experiments; microinjections were delivered either through stainless steel cannulae or a microdialysis probe during novel (first day) or familiar (second day) taste presentation. For all groups, the total volume of solution ( $0.5 \mu \mathrm{l}$ per injection locus) was delivered over 1 min. Injection needles were left inside of the cannulae for 1 additional minute to allow diffusion of the injected solution into the tissue and to minimize suction of the liquid back along the injection track. Doses of muscimol and bicuculline were based on previous behavioral studies demonstrating the modulating effects of GABA receptor manipulations in learning tasks (Morón et al., 2002).

Microdialysis. Rats were habituated to drink water from 2 graduated bottles for $15 \mathrm{~min} / \mathrm{d}$ for $4 \mathrm{~d}$ in the microdialysis chamber. On the day 5 (first novel taste presentation) or day 6 (second familiar) preference taste trial, the microdialysis procedure commenced in accordance with a previously described protocol (Miranda and Bermúdez-Rattoni, 1998; 


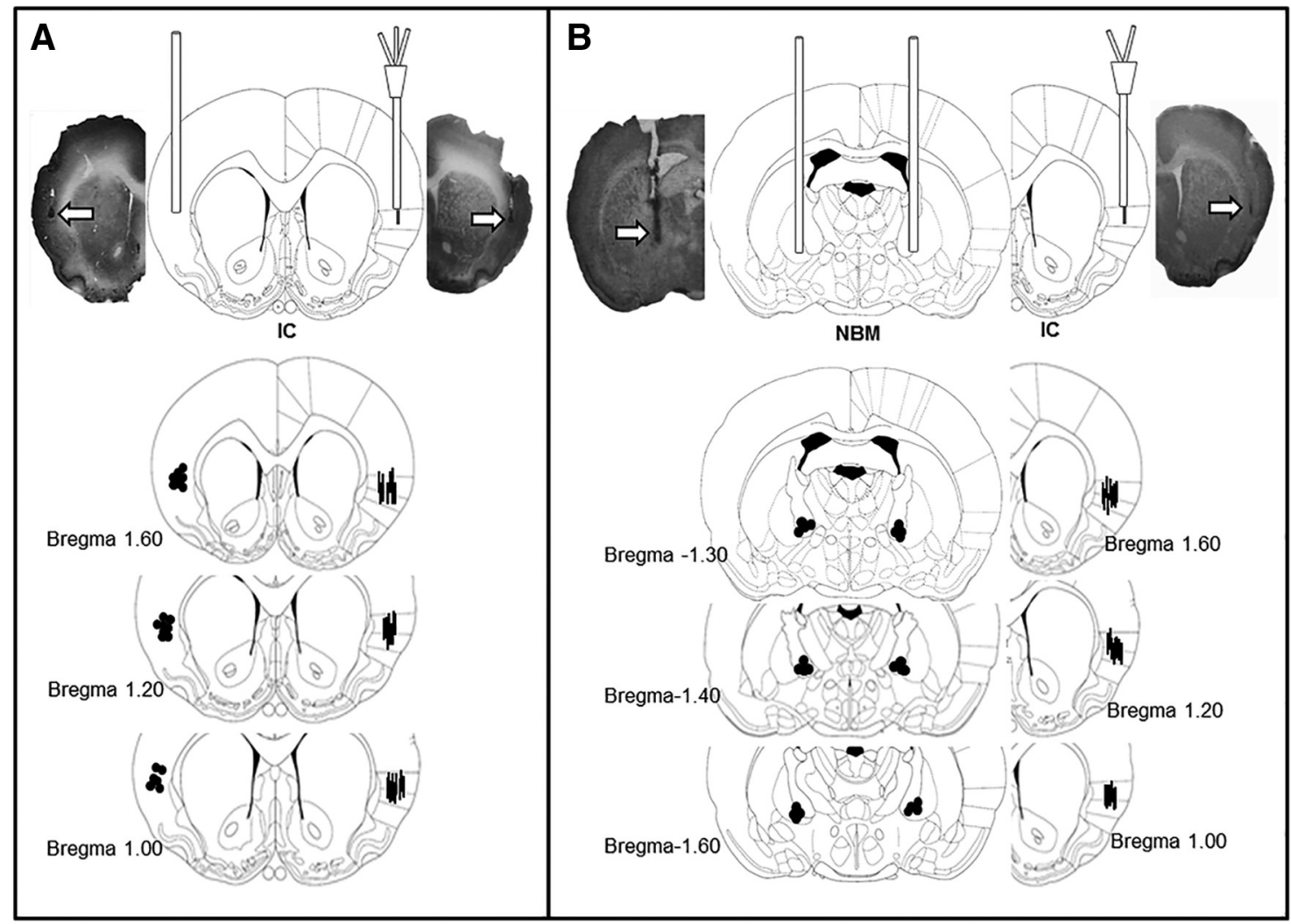

Figure 1. Coronal section diagrams and representative photomicrographs of cannulae and probe placement in the IC and NBM. $A$, Groups with one stainless steel cannula in the left IC and one dual probe (injector and microdialysis probe) in the right IC. B, Groups with bilateral NBM injection cannulae and one cannula/microdialysis probe in the right IC. Arrows (above) and dots (below) show locations of stainless steel cannulae. Lines show microdialysis probes (modified from Paxinos and Watson, 1998).

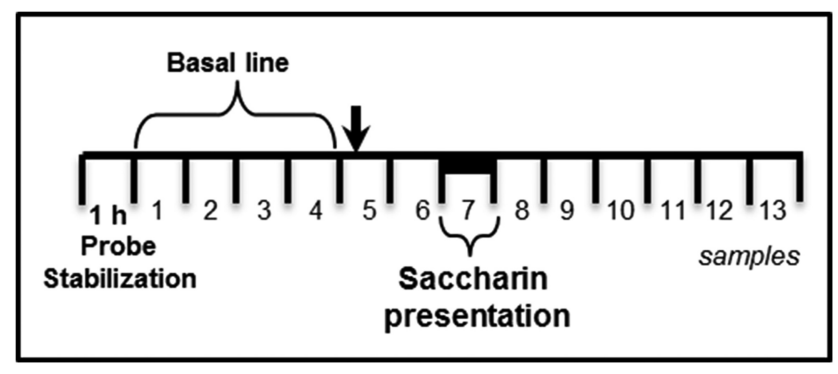

Figure 2. Microdialysis in freely moving rats. A total of $13 / 15$ min samples were collected from the right IC during novel or familiar taste presentation. The black arrow indicates drug injection and the black bar saccharin presentation

1999). Microdialysis probes (BASi MD 2204 or MD 2264) were placed in the IC probe guide cannulae and then microdialysis was started by connecting the probe inlet to a microinjection pump system (CMA Microdialysis) that circulated the probe continuously with Ringer's solution $\left(118 \mathrm{~mm} \mathrm{NaCl}, 4.7 \mathrm{~mm} \mathrm{KCl}, 2.5 \mathrm{mM} \mathrm{CaCl}_{2}\right.$, and $10 \mu \mathrm{M}$ neostigmine to prevent $\mathrm{ACh}$ degradation) at a rate of $2 \mu \mathrm{l} / \mathrm{min}$. As summarized in Figure 2, the perfusion exudate from the first $60 \mathrm{~min}$ was discarded and then samples were collected every 15 min thereafter. A total of 13 samples were collected on each sampling day. Microinjections were delivered immediately before collection of sample 5 and, 30 min later, two graduated bottles (one with water, one with saccharin solution) were presented while sample 7 was collected. An additional six samples were collected before the microdialysis procedure was concluded. All of the microdialysis samples were immediately frozen at $-30^{\circ} \mathrm{C}$ and stored until they were analyzed by high-performance liquid chromatography (HPLC).

ACh quantitation. Levels of ACh in microdialysis samples were quantitated by HPLC and electrochemical detection as described previously
(Miranda and Bermúdez-Rattoni, 1999). Briefly, each dialysate sample was assayed using an $\mathrm{ACh} /$ choline chromatographic assay kit (BASi) consisting of an analytical polymeric reversed-phase column (BASi MF6150 ) and an ACh/choline immobilized enzyme reactor (IMER, BASi MF-6151). The mobile phase (flow rate, $1 \mathrm{ml} / \mathrm{min}$ ) consisted of a $50 \mathrm{~mm}$ sodium phosphate buffer, $\mathrm{pH} 8.5$, supplemented with $0.05 \%$ Kathon reagent (BASi), a broad-spectrum antimicrobial suitable for enzyme preservation. ACh was separated in the analytical column and hydrolyzed into acetate and choline by acetylcholinesterase in the IMER. The choline product was then oxidized by choline oxidase into betaine and hydrogen peroxide. Hydrogen peroxide was detected electrochemically by a platinum working electrode at $+500 \mathrm{mV}$ with an $\mathrm{Ag} / \mathrm{AgCl}$ reference electrode. The sensitivity limit was $\sim 0.1 \mathrm{pmol}$ and the signal/noise ratio was $>2$. A linear regression curve was made using ACh standards and the compound peak areas for the samples were compared with those of the standards. ACh levels were calculated as $\mathrm{pmol} / 20 \mu \mathrm{l}$.

GABA quantitation. Microdialysis samples were assayed for GABA content by HPLC (Dionex Ultimate 3000; Thermo Scientific, with Chromeleon 6.8 software integrator for data analysis) with fluorescence detection (excitation at $337 \mathrm{~nm}$, emission at $442 \mathrm{~nm}$ ), after $o$-phthaldehyde derivatization of the amino acid as described previously (Giorgetti et al., 2000). In summary, the volume of dialysate (25 $\mu \mathrm{l}$ ) was mixed with $25 \mu \mathrm{l}$ of $o$-phthaldehyde in a tube and the mixture was injected $2 \mathrm{~min}$ later into a $5 \mu \mathrm{m} \mathrm{C18}$ column $(100 \times 4.6 \mathrm{~mm}$; Hypersil Gold, Thermo Scientific) at $20^{\circ} \mathrm{C}$. A mobile phase of potassium acetate $(0.1 \mathrm{M})$ adjusted to $\mathrm{pH} 5.5$ with glacial acetic acid was used. A gradient $25 \%$ methanol/75\% mobile phase was used with a 1.5 $\mathrm{ml} / \mathrm{min}$ flow rate. A linear regression curve was made using three GABA standards and the peak areas of the compound in the samples were compared with those of the standards; the minimum detectable concentration was $1 \mathrm{pmol} / \mu \mathrm{l}$.

Histology. One day after completing the experimental procedures, the rats were deeply anesthetized with pentobarbital and perfused 


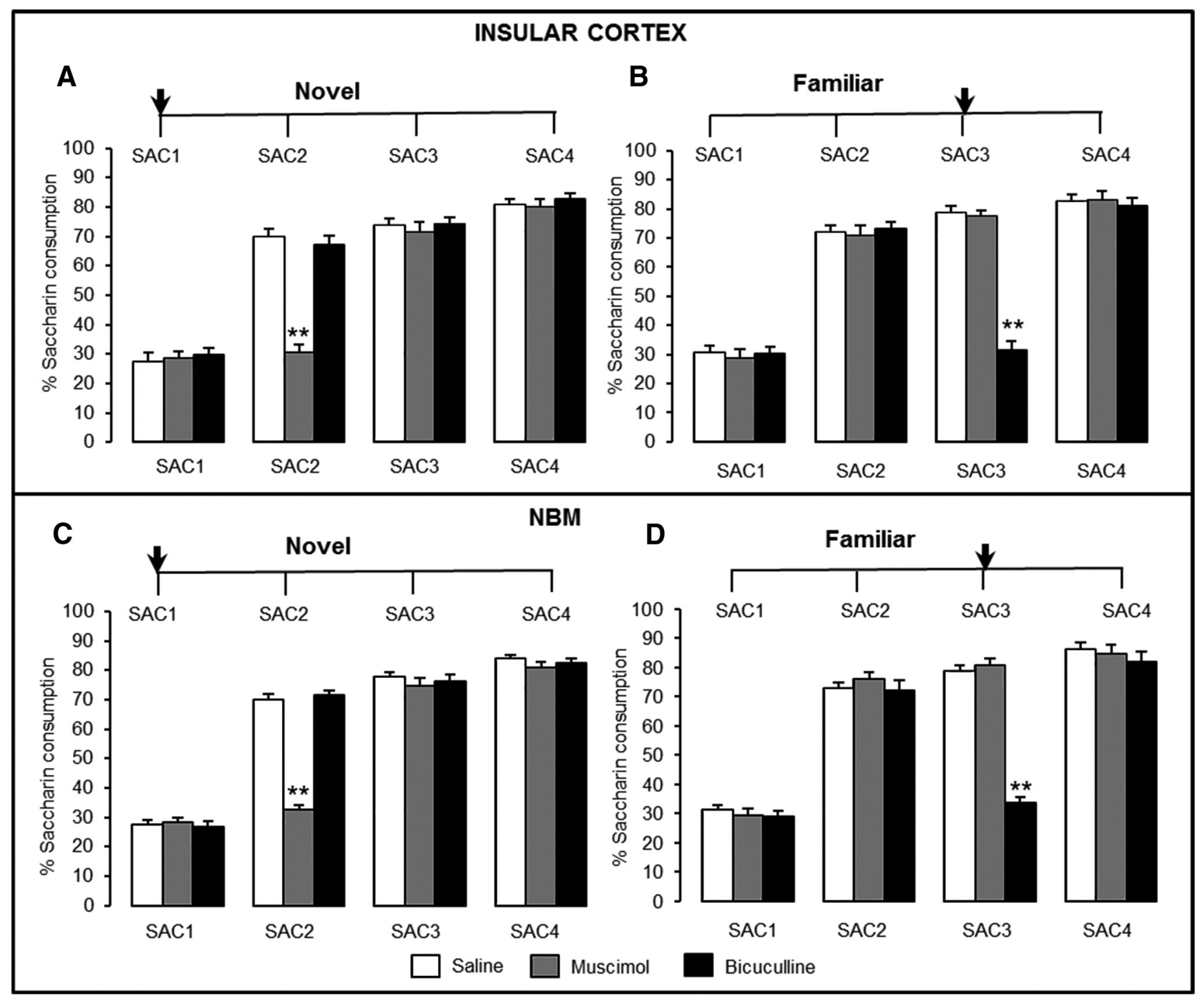

Figure 3. Taste preference effects of bilateral intra-IC injections and intra-NBM injections of muscimol and bicuculline. Consumption of saccharin as a novel tastant (A: saline, $n=11$; muscimol, $n=10$; bicuculline, $n=11$ ) and ( $\boldsymbol{C}$ : saline, $n=12 ;$ muscimol, $n=12$; bicuculline, $n=12)$. Consumption of saccharin as a familiar tastant (memory retrieval) ( $\boldsymbol{B}:$ saline, $n=$ 12; muscimol, $n=12$; bicuculline, $n=13$ ) and ( $\boldsymbol{D}$ : saline, $n=10$; muscimol, $n=11$; bicuculline, $n=11)$. Data are shown as the percentage saccharin consumption \pm SEM, ${ }^{*} p<0.05$, ${ }^{* *} p<0.001$ versus control. Arrows indicate injection day.

transcardially with $4 \%$ formaldehyde in $0.9 \%$ saline. The brains were placed in formaldehyde overnight and then transferred to a $30 \%$ buffered sucrose solution and stored at $4^{\circ} \mathrm{C}$. Coronal sections $(50 \mu \mathrm{m}$ thick) taken through the areas where the microdialysis probe and injectors had been were stained with cresyl violet and inspected under stereoscopic light (Fig. 1). Only data from rats with injector/probe tips confirmed to be located within the NBM and IC were included in the analysis.

Statistical analysis. Repeated-measures ANOVAs (rmANOVAs) of the percentage of saccharin consumption on taste preference trials days (SAC1-SAC4) were performed between groups and between each treatment day, followed by pairwise multiple-comparison procedures (Bonferroni $t$ tests) as appropriate. $p$-values $<0.05$ were considered significant and all datum values are expressed as mean \pm SEM. rmANOVAs of neurotransmitter levels [i.e., ACh (pmol/20 $\mu \mathrm{l}$ ) and GABA (pmol/25 $\mu \mathrm{l})$ ] were performed between groups, dialysis samples (1-13), and treatment day (novel, familiar). To analyze the source of differences detected, simple paired $t$ tests were performed for each group's samples when appropriate.

\section{Results}

Cannula and probe placement verification and baseline water consumption

Only rats confirmed to have their guide cannulae and/or microdialysis probe in the IC and the NBM (bilaterally) were included in the data analyses (Fig. 1). Forty (17\%) cannulated rats were excluded due to misplacement of cannulae/injectors or the probe. Baseline water consumption (average of $15 \pm 3 \mathrm{ml}$ of water consumed per bottle and $30 \pm \mathrm{ml}$ total water intake per day) was similar between groups in all of the taste memory experiments below (data not shown).

IC $\mathrm{GABA}_{\mathrm{A}}$ receptor agonism, but not antagonism, before novel taste consumption disrupted taste memory formation First, in rats with IC bilateral stainless steel cannulae, we evaluated whether activation of $\mathrm{GABA}_{\mathrm{A}}$ receptors in the IC with the agonist muscimol or inhibition with the antagonist bicuculline affects the formation and/or retrieval of taste preference memory 
(Fig. $3 A, B$ ). Control rats receiving saline development saccharin preference during 3 subsequent days, as expected, exhibited a significant increase in saccharin consumption after a single taste presentation (SAC2) and maintained this preference for the subsequent $3 \mathrm{~d}$ (SAC3 and SAC4). When agonist or antagonist injections were made before novel taste consumption day 1 (SAC1; Fig. $3 A$ ), the rmANOVA of the percentage of saccharin consumed on each trial day (see Materials and Methods for calculation definition) revealed significant effects of group $\left(F_{(2,29)}=\right.$ $66.4, p<0.001)$ and treatment day $\left(F_{(3,124)}=1833.9, p<0.001\right)$ and a significant group $\times$ treatment day interaction $\left(F_{(6,121)}=\right.$ $130.8, p<0.001)$. The three groups had similar levels of water $(14.1 \pm 3.0 \mathrm{ml})$ and saccharin $(4.0 \pm 3.4 \mathrm{ml})$ consumption during day 1 (\%SAC1 values = saline, $27.3 \pm 1.3 \%$; muscimol, $28.5 \pm 1.3 \%$; bicuculline, $29.7 \pm 1.4 \% ; p>0.05)$, indicating that the intra-IC injections had no acute effect on motivation or liquid consumption. During preference day 2 (SAC2), the muscimol group did not show a significant increase from SAC1 (Bonferroni test $p<0.05)$. However, post hoc analysis indicated that muscimol group consumption differed significantly from the saline and bicuculline groups during SAC2 (both $p<0.001$ ). All groups showed a significant increase in consumption during SAC3 and SAC4 compared with SAC1 (Bonferroni test $p<0.001$ ). These results indicate that $\mathrm{GABA}_{\mathrm{A}}$ receptor agonism, but not antagonism, in the IC during novel taste presentation disrupted taste memory formation.

IC $\mathrm{GABA}_{\mathrm{A}}$ receptor antagonism, but not agonism, before familiar taste consumption disrupted taste memory retrieval In independent groups, we evaluated the effects of the same muscimol and bicuculline dose bilaterally injected into the IC during memory retrieval of taste preference on SAC3 (Fig. $3 B$ ). rmANOVA of relative saccharin consumption per day revealed a significant effect of group $\left(F_{(2,34)}=117.9, p<\right.$ $0.001)$ and treatment day $\left(F_{(3,144)}=1144.6, p<0.001\right)$ and a significant group $\times$ treatment day interaction $\left(F_{(6,141)}=\right.$ $146.5, p<0.001)$. During SAC2, all groups showed a significant increase compared with SAC1 (Bonferroni test $p<0.05$ ). However, during SAC3, when injections were made before consumption, only the saline and muscimol groups showed a significant increase in SAC1 consumption (both $p<0.001$ ). Post hoc analysis revealed no significant intergroup differences during SAC1, SAC2, or SAC4; however, during SAC3, the bicuculline group $(31.3 \pm 1.2 \%)$ differed from that of the saline $(78.6 \pm 1.4 \% ; p<0.001)$ and muscimol $(77.6 \pm 1.0 \% ; p<$ $0.001)$ groups. Nevertheless, during SAC4, all groups showed the same degree of taste preference and differed significantly from SAC1 consumption (Bonferroni test, all $p<0.001$ ). These results indicate that $\mathrm{GABA}_{\mathrm{A}}$ receptor antagonism in the IC blocks taste memory retrieval, whereas agonism of these receptors had no effect on taste preference retrieval.

\section{$\mathrm{NBM} \mathrm{GABA}_{\mathrm{A}}$ receptor agonism, but not antagonism, before novel taste consumption disrupted taste preference memory formation}

In the rat surgery cohorts with NBM bilateral stainless steel cannulae, we evaluated whether the effects induced by the injections of the agonist muscimol or the antagonist bicuculline in the IC could be duplicated when they were administered in the NBM (Fig. 3C,D). As observed in the IC groups, control rats exhibited a significant increase in saccharin consumption after a single taste presentation (SAC2) and maintained this preference during SAC3 and SAC4. When injections were made during novel taste presentation (SAC1; Fig. 3C), rmANOVA of percentage saccharin consumption revealed significant effects of group $\left(F_{(2,33)}=97.9, p<0.001\right)$ and treatment day $\left(F_{(3,140)}=1551.1, p<0.001\right)$, as well as a significant group $\times$ treatment day interaction $\left(F_{(6,137)}=\right.$ $126.2, p<0.001)$. The consumption volume of water $(15.6 \pm$ $3.8 \mathrm{ml})$ and saccharin $(4.4 \pm 3.2 \mathrm{ml})$ during day 1 across the groups during SAC1 was similar $(\% \mathrm{SAC} 1=$ saline, $27.6 \pm$ $1.4 \%$; muscimol, $28.3 \pm 0.98 \%$; and bicuculline, $26.9 \pm 1.3 \%$; $p>0.05)$, indicating that the intra-NBM injections during novel taste exposure did not affect motivation to drink or liquid consumption. The saline and bicuculline groups significantly increased their consumption during SAC2 compared with SAC1 (both $p<0.001$ ), but the muscimol group did not. Furthermore, post hoc analysis revealed that, during SAC2, the muscimol group $(32.6 \pm 1.1 \%)$ differed from the saline $(69.9 \pm 1.3 \% ; p<0.001)$ and bicuculline $(71.4 \pm 1.1 \% ; p<$ $0.001)$ groups. On the following days, all groups showed a taste preference and had similar levels of consumption during SAC3 (saline, $77.9 \pm 1.0 \%$; muscimol, $75.7 \pm 1.3 \%$; bicuculline, $76.3 \pm 0.8 \% ; p>0.05)$ and SAC4 (saline, $83.9 \pm 1.3 \%$; muscimol, $80.9 \pm 1.2 \%$; bicuculline, $82.3 \pm 1.2 \%$; $p>0.05)$ that significantly differed from SAC1 (Bonferroni test, all $p<$ $0.001)$. These results were similar to those observed when injections were made in the IC and indicate that $\mathrm{GABA}_{\mathrm{A}}$ receptor agonism in the NBM also disrupted the formation of taste preference memory, whereas antagonism of these receptors had no effect on memory formation.

\section{$\mathrm{NBM} \mathrm{GABA}_{\mathrm{A}}$ receptor antagonism, but not agonism, before} familiar taste consumption prevented taste memory retrieval The effect of bilateral intra-NBM muscimol and bicuculline on taste memory retrieval was evaluated in separate groups of rats (Fig. 3D). rmANOVA of percentage saccharin consumption revealed significant effects of group $\left(F_{(2,29)}=158.0, p<\right.$ $0.001)$ and treatment day $\left(F_{(3,124)}=1055.3, p<0.001\right)$, as well as a significant group $\times$ treatment day interaction $\left(F_{(6,121)}=\right.$ $137.2, p<0.001)$. During SAC2, all groups showed a significant increase in consumption compared with SAC1 (Bonferroni test, all $p<0.001)$. However, during SAC3, when injections were made, consumption in the saline and muscimol groups differed from SAC1 $(p<0.001)$, but not for the bicuculline group. A post hoc analysis revealed that SAC3 consumption of the bicuculline group $(33.5 \pm 2.0 \%)$ differed from that of the saline group $(78.8 \pm 0.9 \%$; $p<0.001)$ and the muscimol group $(80.8 \pm 1.1 \% ; p<0.001)$. These results indicate that $\mathrm{GABA}_{\mathrm{A}}$ receptor antagonism in the NBM prevented retrieval of familiar taste memory, whereas agonism of these receptors had no effect on familiar preference expression. Overall, these results indicate that, during taste memory formation or retrieval, $\mathrm{GABA}_{\mathrm{A}}$ receptors in the NBM play a function similar to that of the receptors in the IC.

\section{$\mathrm{GABA}_{\mathrm{A}}$ receptor agonism in the $\mathrm{NBM}$ or IC before novel taste presentation prevented cortical $\mathrm{ACh}$ increase and taste memory formation}

Our second goal was to determine whether effects induced by the activation of $\mathrm{GABA}_{\mathrm{A}}$ receptors in the NBM and IC during taste memory formation or retrieval also correlate with ACh cortical release. Accordingly, the effects of bilateral intra-IC and intra-NBM muscimol and bicuculline on cortical ACh release were determined by microdialysis during novel or familiar taste presentation in the rat surgery cohorts with bilat- 


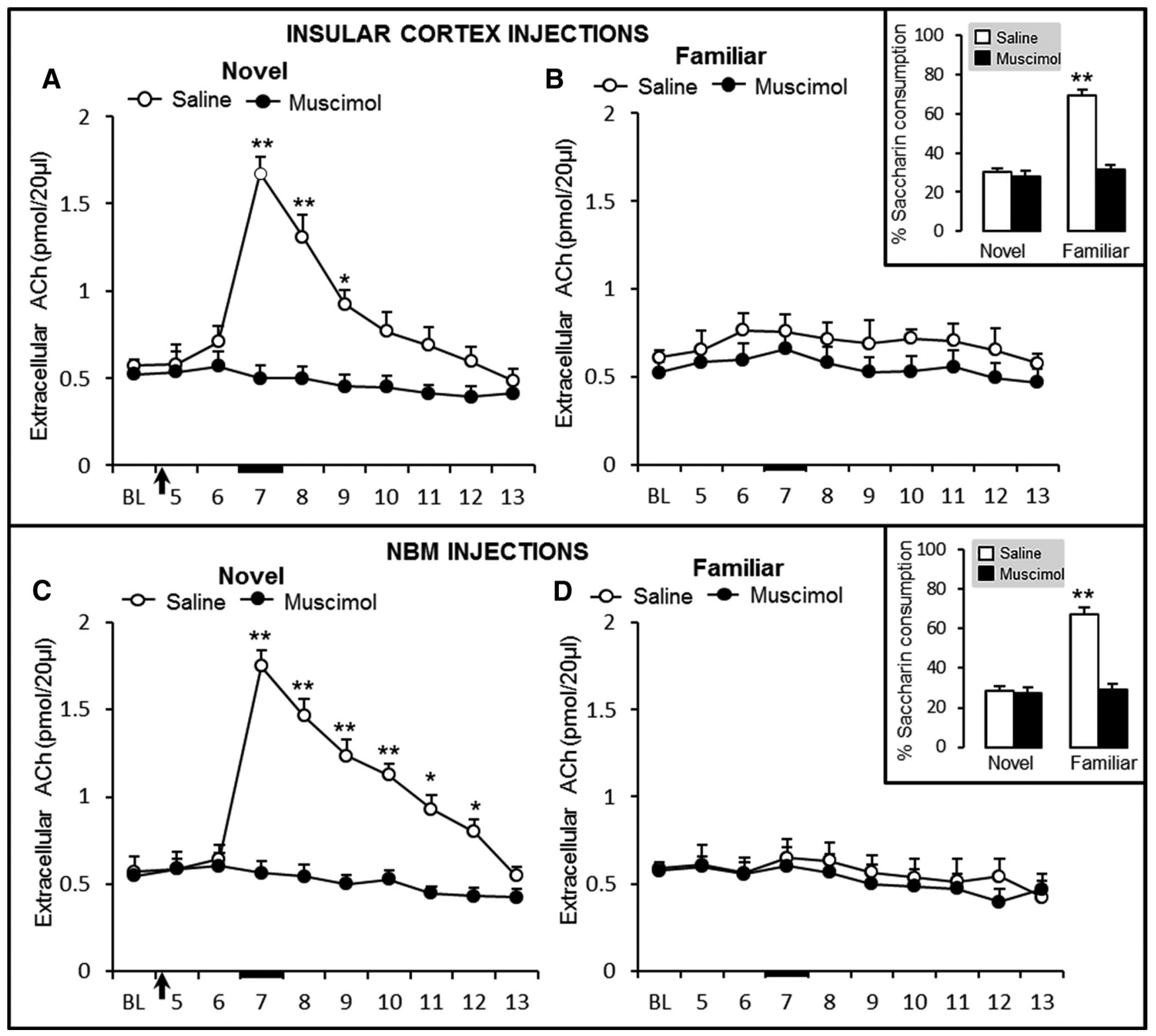

Figure 4. Extracellular ACh levels in the IC during novel taste presentation and IC injections $(\boldsymbol{A})$ and familiar taste presentation in groups that received IC injections $24 \mathrm{~h}$ earlier $(\boldsymbol{B})($ saline, $n=5$; muscimol, $n=6$ ). Novel taste presentation and NBM injections $(\boldsymbol{C})$ and familiar taste presentation in groups that received NBM injections $24 \mathrm{~h}$ earlier $(\boldsymbol{D})($ saline, $n=6 ;$ muscimol, $n=5)$. Black arrow indicates IC saline or muscimol injection and the black bar indicates saccharin presentation. Independent groups in $\boldsymbol{A}-\boldsymbol{D}:{ }^{*} p<0.05,{ }^{* *} p<0.001$ versus control. Inset, Percentage saccharin consumption of each group during the microdialysis procedure.

eral stainless steel cannulae directed bilaterally to the NBM or IC and with microdialysis IC guide cannula (Fig. 1). As described previously (Miranda et al., 2000), novel taste presentation significantly increased the extracellular ACh levels in the IC of control (saline) groups (Fig. $4 A, C$ ). rmANOVA of ACh levels during the novel taste presentation and IC injections during the microdialysis session revealed significant group $\left(F_{(1,9)}=25.7, p<0.001\right)$ and sample $\left(F_{(9,100)}=27.6\right.$, $p<0.001)$ effects, as well as a significant group $\times$ sample interaction $\left(F_{(9,98)}=22.6, p<0.001\right.$; Fig. $\left.4 A\right)$. Paired $t$ tests indicated that ACh levels in the IC differed significantly between the saline and muscimol groups in sample $7\left(t_{10}=11.2\right.$, $p<0.001)$, sample $8\left(t_{10}=7.7, p<0.001\right)$, and sample 9 $\left(t_{10}=4.5, p=0.022\right)$; indicating that activation of $\mathrm{GABA}_{\mathrm{A}}$ receptors in the IC disrupted cortical ACh release during novel taste presentation (Fig. 4A). Conversely, rmANOVA of ACh levels during the familiar taste presentation microdialysis session revealed no significant group $\left(F_{(1,9)}=2.4, p=0.2\right)$ or sample $\left(F_{(9,100)}=3.3, p<0.001\right)$ effects and no group $\times$ sample interaction $\left(F_{(9,98)}=0.6, p=0.8\right)$, indicating that familiar taste presentation, or muscimol injections made $24 \mathrm{~h}$ earlier, did not induce any change in IC extracellular ACh levels (Fig. 4B).

The consumption measured during this microdialysis session showed the development of taste preference in control rats because they exhibited a significant increase in saccharin consumption after a single taste presentation (Fig. $4 B$, inset), as revealed by rmANOVA of percentage saccharin consumption during the microdialysis and IC muscimol injections, showing significant effects of group $\left(F_{(1,9)}=204.0, p<0.001\right)$ and sample $\left(F_{(1,20)}=\right.$ 279.6, $p<0.001)$, as well as a significant group $\times$ sample interaction $\left(F_{(1,18)}=254.773, p<0.001\right)$. Saccharin consumption 
differed between the novel and familiar presentation in the saline group (paired $t$ test, $p<0.001$ ), but not in the muscimol group $(p>0.05)$. Saccharin consumption differed significantly between the saline and muscimol groups in the familiar taste presentation $(p<0.001)$. These results demonstrate that agonism of $\mathrm{GABA}_{\mathrm{A}}$ receptors in the IC disrupted cortical ACh release during novel taste consumption and prevented taste memory formation.

Moreover, when bilateral muscimol injections were made intra-NBM (in other independent groups), we found similar effects as those induced by IC injections during novel taste presentation (Fig. 4C). rmANOVA of extracellular cortical ACh levels revealed significant group $\left(F_{(1,9)}=64.2, p<0.001\right)$ and sample effects $\left(F_{(9,100)}=32.1, p<0.001\right)$, as well as a significant group $\times$ sample interaction $\left(F_{(9,98)}=29.2, p<0.001\right)$. Paired $t$ test analysis indicated that ACh levels in the IC differed between the saline and muscimol groups in sample $7\left(t_{10}=13.4, p<\right.$ $0.001)$, sample $8\left(t_{10}=10.4, p<0.001\right)$, sample $9\left(t_{10}=8.3, p<\right.$ $0.001)$, sample $10\left(t_{10}=6.7, p<0.001\right)$, sample $11\left(t_{10}=5.4\right.$, $p<0.05)$, and sample $12(t=4.2, p<0.05)$. Furthermore, as summarized in Figure 4D, 24 h later, the extracellular ACh levels during the familiar taste presentation were similar across groups $\left(\operatorname{rmANOVA} F_{(1,9)}=1.1, p=0.33\right)$ and samples $\left(F_{(9,100)}=4.5\right.$, $p<0.001)$, with no group $\times$ sample interaction $\left(F_{(9,98)}=0.4\right.$, $p=0.94)$. These data indicate that NBM muscimol injections during novel taste presentation disrupted cortical ACh release (Fig. 4D, inset) and replicated the effects of IC muscimol injections described above, which showed that familiar taste presentation did not induce any change in cortical extracellular ACh levels. Furthermore, the saccharin consumptions measured during the microdialysis session and NBM injections showed results similar to those observed in the IC. rmANOVA of percentage saccharin consumption during microdialysis showed significant $\operatorname{group}\left(F_{(1,9)}=201.6, p<0.001\right)$ and sample $\left(F_{(1,20)}=113.6, p<\right.$ $0.001)$ effects, as well as a significant group $\times$ sample interaction $\left(F_{(1,18)}=117.5, p<0.001\right.$; Fig. $4 D$, inset $)$. Paired $t$ test analysis showed a significant difference in consumption between the novel and familiar presentations in the saline group $(p<0.001)$, but not in the muscimol group ( $p>0.05)$. During familiar taste presentation, percentage of saccharin solution consumption differed between the saline and muscimol groups $(p<0.001)$. These results demonstrate that agonism of $\mathrm{GABA}_{\mathrm{A}}$ receptors in the NBM disrupted cortical ACh release during novel taste exposure and prevented taste memory formation.

\section{$\mathrm{GABA}_{\mathrm{A}}$ receptor antagonism in the IC or NBM before familiar taste presentation increased cortical ACh levels and disrupted taste memory retrieval}

Given that $\mathrm{GABA}_{\mathrm{A}}$ receptor antagonism in the NBM prevented taste familiar memory retrieval, we also evaluated, in another set of independent groups, the extracellular cortical ACh levels during familiar taste presentation and bicuculline bilateral injections in the IC or NBM. Rats were first exposed to the novel taste without any injection in the IC (Fig. $5 A$ ) or in the NBM (Fig. 5C). As expected, all groups showed a significant increase in extracellular ACh levels during novel taste presentation. rmANOVA indicated no differences between IC groups $\left(F_{(1,8)}=4.1, p=0.14\right)$ or samples $\left(F_{(9,90)}=102.2, p<\right.$ $0.001)$ and there was no group $\times$ sample interaction $\left(F_{(9,88)}=\right.$ $0.4, p=0.94)$. ACh levels in sample 6 differed significantly from those in samples $7,8,9$, and 10 in both the saline and the bicuculline group (paired $t$ tests, both $p<0.001$ ). Extracellular ACh levels did not differ significantly between the two groups in any of the samples (Fig. 5A). Similar cortical extra- cellular ACh levels, during exposure to a novel taste, were found in the NBM injection groups (Fig. 5C); rmANOVA of extracellular ACh levels in the IC revealed a significant effect of sample $\left(F_{(9,100)}=49.9, p<0.001\right)$, but not of group $\left(F_{(1,9)}\right.$ $=0.2, p=0.70)$, and no group $\times$ sample interaction $\left(F_{(9,98)}=\right.$ $0.8, p=0.668)$. ACh levels in sample 6 differed from ACh levels in samples $7,8,9$, and 10 in each of the two groups (paired $t$ tests, $p<0.001$ ). Nevertheless, during familiar saccharin presentation and bicuculline injections in the IC (Fig. $5 B)$, rmANOVA of extracellular ACh levels revealed significant effects of group $\left(F_{(1,8)}=211.7, p<0.001\right)$ and sample $\left(F_{(9,90)}=25.9, p<0.001\right)$ and a significant group $\times$ sample interaction $\left(F_{(9,88)}=15.9, p<0.001\right)$. ACh levels differed between the saline and bicuculline groups in sample $7\left(t_{9}=\right.$ $10.4, p<0.001)$, sample $8\left(t_{9}=9.1, p<0.001\right)$, sample $9\left(t_{9}=\right.$ $6.9, p<0.001)$, sample $10\left(t_{9}=5.7, p<0.001\right)$, and sample 11 $\left(t_{9}=4.5, p<0.05\right)$. These data reveal that blocking the $\mathrm{GABA}_{\mathrm{A}}$ receptor in the IC during familiar taste retrieval induces a significant increase in cortical ACh. These increments in ACh levels correlated with the decrease in consumption observed in the bicuculline group that was not able to retrieve taste memory preference; rmANOVA of percentage of consumption revealed significant effects of group $\left(F_{(1,8)}=331.9\right.$, $p<0.001)$ and sample $\left(F_{(1,18)}=115.6, p<0.001\right)$ on saccharin consumption (Fig. $5 B$, inset), as well as a significant group $\times$ sample interaction $\left(F_{(1,16)}=98.1, p<0.001\right)$. Saccharin consumption differed between the novel and familiar taste presentations in the saline group (paired $t$ test $p<0.001$ ), but not in the bicuculline group $(p>0.05)$. Saccharin consumption differed between the saline and bicuculline groups in the familiar taste presentation $(p<0.001)$. These results indicate that $\mathrm{GABA}_{\mathrm{A}}$ receptor antagonism in the IC, which disrupted taste memory retrieval, increased cortical ACh release during familiar taste retrieval to a level similar to that observed in the novel presentation.

Once again, the effects of intra-NBM bicuculline injections on cortical extracellular ACh levels during the familiar taste presentation were similar to those observed when the antagonist was injected in the IC (Fig. 5D). rmANOVA of ACh levels revealed significant effects of group $\left(F_{(1,9)}=19.1, p<0.05\right)$ and sample $\left(F_{(9,100)}=27.8, p<0.001\right)$, as well as a significant group $\times$ sample interaction $\left(F_{(9,98)}=17.7, p<0.001\right)$. ACh levels differed between the saline and muscimol groups in sample $7\left(t_{10}=8.3\right.$, $p<0.001)$, sample $8\left(t_{10}=6.7, p<0.001\right)$, sample $9\left(t_{10}=6.2\right.$, $p<0.001)$, and sample $10\left(t_{10}=4.9, p<0.05\right)$. These results showed that $\mathrm{GABA}_{\mathrm{A}}$ receptor antagonism in the NBM during familiar taste consumption increased cortical ACh levels to levels similar to those observed during novel first taste presentation. Accordingly, the results also showed that taste memory retrieval is sensitive to $\mathrm{GABA}_{\mathrm{A}}$ receptor antagonism in the NBM because the bicuculline group did not show any taste preference during familiar taste presentation, as revealed by rmANOVA of the percentage of saccharin consumption showing significant effects of group $\left(F_{(1,9)}=135.5, p<0.001\right)$ and samples $\left(F_{(1,20)}=133.3\right.$, $p<0.001)$, as well as a significant group $\times$ sample interaction $\left(F_{(1,18)}=128.7, p<0.001\right.$; Fig. $5 D$, inset $)$. Overall, these results show that familiar taste presentation did not induce any change in IC extracellular ACh levels and demonstrate that $\mathrm{GABA}_{\mathrm{A}}$ receptor antagonism in the NBM or IC is able to increase cholinergic activity significantly, which also altered taste memory retrieval. 


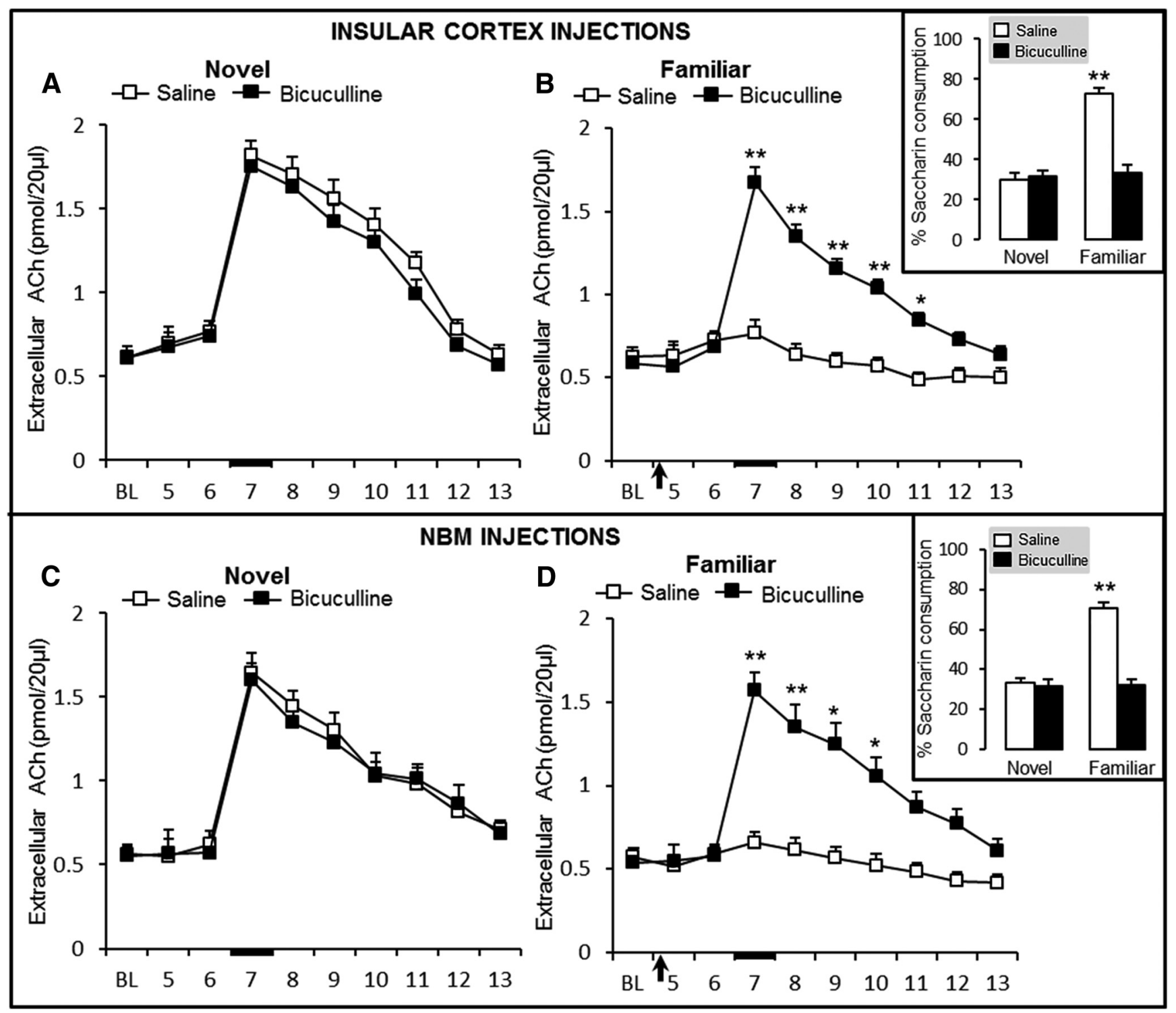

Figure 5. Extracellular ACh levels in the IC during novel taste presentation and IC injections and novel taste presentation $(\boldsymbol{A})$ and familiar taste presentation in groups that received IC injections $24 \mathrm{~h}$ earlier $(\boldsymbol{B})$ (saline, $n=5$; bicuculline, $n=5)$. C, $\boldsymbol{D}$, Novel taste presentation and NBM injections $(\boldsymbol{C})$ and familiar taste presentation in groups that received NBM injections $24 \mathrm{~h}$ earlier ( $\boldsymbol{D})$ (saline, $n=5$; bicuculline, $n=6$ ). Black arrow indicates IC saline or bicuculline injection and black bar indicates saccharin presentation. Independent groups in $\boldsymbol{A}-\boldsymbol{D}$ : ${ }^{*} p<0.05$, ${ }^{* *} p<0.001$ versus control. Inset, Percentage saccharin consumption during the microdialysis procedure.

Extracellular GABA levels in the IC during consumption of a novel versus familiar taste

The above results strongly suggest that GABAergic transmission enhancement induced by muscimol injections disrupts taste memory formation, whereas GABAergic transmission increment during familiar consumption has no effect on memory recall. On the contrary, reduction of GABAergic transmission induced by bicuculline during consumption of a novel taste has no effect on novelty learning, but antagonism during consumption of familiar taste disrupted taste memory retrieval. Therefore, to corroborate this differential GABA involvement in taste memory formation and retrieval, we evaluated the extracellular GABA levels in the IC during the novel and familiar taste presentations by microdialysis in freely moving rats (Fig. 6). The results showed that GABA levels decreased during novel presentation and increased during familiar taste presentation. rmANOVA of GABA levels in the IC revealed significant effects of group $\left(F_{(1,8)}=16.2\right.$, $p<0.05)$ and sample $\left(F_{(9,90)}=2.9, p<0.05\right)$, as well as a group $\times$ sample interaction $\left(F_{(9,88)}=7.7, p<0.001\right)$. GABA levels differed between the novel and familiar taste presentations in sample $7\left(t_{9}=5.2, p<0.05\right)$, sample $8\left(t_{9}=5.4, p<0.05\right)$, sample 9 $\left(t_{9}=5.3, p<0.05\right)$, and sample $10\left(t_{9}=4.3\right.$, sample $\left.p<0.05\right)$. In addition, the baseline differed from the GABA levels in samples 7 , 8,9 , and 10 (all $p<0.05$ ) in both groups. As expected, the percentage of saccharin consumption differed significantly between the novel and familiar taste presentations during microdialysis $\left(t_{9}=24.6, p<0.001\right)$ (Fig. 6 , inset). These results demonstrated that consumption of a novel taste induced a reduction in the extracellular GABA levels and that familiar taste consumption increased the levels of extracellular GABA in the IC; they also strongly correlate with the agonism and antagonism effects observed during taste learning and retrieval.

\section{Discussion}

This work demonstrates interactions between cholinergic and GABAergic systems during taste learning and retrieval and pro- 


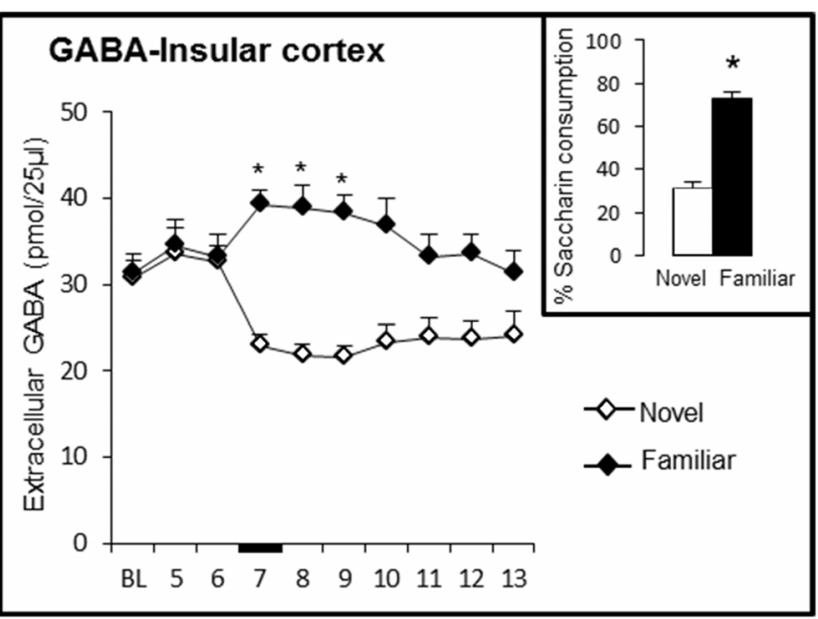

Figure 6. Extracellular GABA levels in the IC during novel and familiar saccharin taste presentation (novel, $n=5$; familiar, $n=5$ ). Black bar indicates saccharin presentation ( ${ }^{*} p<0.05$ vs control). Inset, Percentage saccharin consumption of each group during the microdialysis procedure. BL, Baseline.

vides evidence in support of the hypothesis that cortical ACh release induced by novel taste consumption is required for taste memory formation, whereas GABA activity is necessary for memory retrieval because of its role in modulating cortical ACh levels during recognition of a familiar taste. The present results showed, for the first time in a freely moving rat model, that $\mathrm{GABA}_{\mathrm{A}}$ receptors mediated changes of ACh levels in the IC, which in normal conditions are positively correlated with the ability to acquire taste memory and negatively correlated with taste memory retrieval.

We found that activation of $\mathrm{GABA}_{\mathrm{A}}$ receptors in the IC or the NBM disrupted taste memory formation but did not impair the retrieval of taste memory. Moreover, rats injected with bicuculline were able to develop a taste preference, but not to retrieve a taste memory, indicating that $\mathrm{GABA}_{\mathrm{A}}$ receptor inactivation did not impede novel memory formation but disrupted memory retrieval. Accordingly, novel taste consumption induced extracellular GABA decrements, but familiar taste consumption increased extracellular GABA levels in the IC. These opposite effects mediated by GABA receptors during novelty and familiarity indicate a change in the balance between cortical excitation and inhibition induced by taste memory formation, switching in favor of cholinergic excitation during novelty processing and changing to GABAergic inhibition during familiar taste memory retrieval.

Electrophysiological evidence has shown that GABAergic activity in the IC is necessary for proper taste information possessing (Ogawa et al., 1998); in addition, pharmacological evidence has shown the involvement of GABA receptors in acquisition and/or retrieval of taste memory. For example, IC microinjection of bicuculline and muscimol (using a significantly higher dose than in the present experiments) impaired either conditioned taste aversion (CTA) acquisition or its latent inhibition (Berman et al., 2000). However, other behavioral data have shown that acquisition and/or consolidation of CTA is not disrupted by muscimol or bicuculline injections in the NBM (Morón et al., 2002). Recently, c-Fos expression has been shown to be elevated in cortical GABAergic interneurons $2 \mathrm{~h}$ after novel taste learning, providing evidence for the involvement of a local cortical circuit during offline processing and consolidation of taste information (Doron and Rosenblum, 2010). Different interpretation and dis- crepancy between previous reports must be considered when histochemical techniques and methods of directly agonizing or antagonizing the GABAergic system are used to assess the dynamics of activity correlated with behavior because these methodologies involve different spatial and temporal resolutions for the explanation of taste information processing.

Our findings indicate that GABAergic neurotransmission in the IC and the NBM functions in an opposing manner during taste memory acquisition versus retrieval and this opposite transmission could modulate cortical ACh activity. During novel taste presentation, $\mathrm{GABA}_{\mathrm{A}}$ receptor agonism produced significant decreases in ACh levels in the IC regardless of whether they were administered into the IC or the NBM. Conversely, during familiar taste consumption, $\mathrm{GABA}_{\mathrm{A}}$ receptor antagonism in the IC or in the NBM increased cortical ACh levels. Overall, our findings are in agreement with evidence suggesting that GABA exerts an inhibitory effect on cholinergic activity, mediating executive aspects of cognitive performance, including the switching between multiple input sources during tasks involving demands on cognitive flexibility (Sarter and Bruno, 2002). The dampening action of GABA upon the cholinergic system may be important for the behavioral outcomes of perceiving novel versus familiar stimuli (Hasselmo and Schnell, 1994; Hasselmo, 1999; Giovannini et al., 2001; Hasselmo et al., 2002; Hasselmo, 2006). It is known that GABAergic basal forebrain projections innervate all areas and layers of the cortex (Mechawar et al., 2000). Cortical GABAergic interneurons have been shown to control the excitability of pyramidal neurons through cell-class-specific direct inhibitory and disynaptic disinhibitory circuitry (Arroyo et al., 2012). The NBM cholinergic neurons provide the major cholinergic innervations to the cortex (Mesulam et al., 1983) and are GABA-ceptive (Záborszky et al., 1986), demonstrating that GABA could inhibit the activity of basal forebrain cholinergic neurons projecting to the cortex (Khateb et al., 1998), although NBM GABAergic neurons that project to similar cortical areas could be exerting similar inhibitory effects (Freund and Gulyás, 1991). In addition to these modulatory projections, cortical cholinergic networks could be regulated by cortical GABAergic interneurons inhibiting ACh release presynaptically (Rasmusson et al., 2007) Nevertheless, despite the evidence for forebrain and cortical circuits in several cortical areas, the cellular and circuit mechanism by which GABA modulates ACh release in the IC has not yet been fully described. Our results indicate that $\mathrm{IC}$ accomplishes the regulatory GABA actions showed in other cortices because the effects of $\mathrm{GABA}_{\mathrm{A}}$ receptor agonists or antagonists in the $\mathrm{NMB}$ or IC on extracellular ACh levels in the IC can be explained by the existence of $\mathrm{GABA}_{\mathrm{A}}$ receptors in the cell body of cholinergic NBM neurons projecting to the $\mathrm{IC}$ and by the existence of $\mathrm{GABA}_{\mathrm{A}}$ receptors in cortical cholinergic terminals.

Taste memory is a representation of the basic characteristics of a gustatory stimulus, the taste hedonic component, and its degree of familiarity. Accordingly, the IC neurons in the gustatory and visceral area receive convergent inputs from baroreceptor, chemoreceptor, gustatory, and nociceptive organs (Hanamori et al., 1998). Therefore, local IC network activity reflects both chemosensory and somatosensory taste-related information that could subserve familiarity processing. Bahar et al. (2004) described how the spiking responses of gustatory cortex multiunits evolved as rats became familiar with a novel taste stimulus, finding that the gustatory cortex increases its response upon familiarization to a specific experienced taste in a distinct temporal phase of its persistent response. This particular response was only evident during the familiar taste exposure, but not $24 \mathrm{~h}$ earlier dur- 
ing taste novel presentation. This opposing dynamic of the novelty versus familiarity responses suggests that persistent cortical representation of taste familiarity requires slow postacquisition processing to develop, which could be related to long-term changes in the patterns of release of several neurotransmitters. Accordingly, during exposure to novel or familiar stimuli, the interplay of NBM inputs to the IC and the cellular distribution of receptors in the local interconnections could be mediating the changes in local spiking responses, which might be related to the activation or inhibition of neurotransmitter receptors and their functional interplay that may extend beyond the acquisition stage.

Currently, a number of reports demonstrate that the activation of several neurotransmitter and intracellular signal transduction systems in the IC outlasts taste presentation and persists beyond memory consolidation (Rosenblum et al., 1997; Gutiérrez et al., 1999; Ferreira et al., 2002; Doron and Rosenblum, 2010; Guzmán-Ramos et al., 2010). The opposing effects of muscimol or bicuculline reported here could be reflecting the balance of activation and inhibition within the local IC networks, including GABAergic cortical interneurons, cholinergic endings in the IC, or GABA inputs from the NBM acting on pyramidal cells (Wood and Richard, 1982; Woolf et al., 1984; Záborszky et al., 1986). Moreover, ACh release may also be modulated or stimulated by other neurotransmitters acting via axoaxonic synapses on cholinergic terminals; for example, recent evidence has implicated histamine in cortical GABA-cholinergic modulation during aversive taste memory formation (Purón-Sierra and Miranda, 2014). Further studies are needed to determine whether neurotransmitters other than histamine have direct effects on GABA release in the IC and how cortical local circuits within the IC subserve taste memory formation and its retrieval.

Finally, it is important to mention that muscimol injections have been reported to cause amnesia in aversive extinction tasks (Ferreira et al., 1992; Markham et al., 2012). It could be that GABA inhibits brain areas involved in fear and aversive learning (e.g., the amygdala) in that extinction is considered inhibitory learning that competes with excitatory conditioning (Akirav, 2007). GABA and glutamate are critically involved in extinction; however, taste preference development (i.e., the current paradigm) is an appetitive task in which a novel sweet taste is not associated with a negative reinforcer such as malaise, as occurs in CTA (Núñez-Jaramillo et al., 2010). Our results support the notion that opposing actions between cholinergic and GABAergic systems are required during rewarded, nonaversive learning (i.e., in appetitive tasks); further studies are needed to evaluate these neurotransmission interactions during aversive memory formation and its retrieval. Moreover, as in many complex tasks, multisensory activation must be involved during taste appetitive learning and the saccharin preference reported here may involve both gustatory and olfactory processing (Capaldi et al., 2004). Future research may reveal whether the odor component in the "saccharin" solution has unique properties that facilitate or potentiate appetitive learning.

Together, the present results demonstrate that $\mathrm{GABA}_{\mathrm{A}}$ receptors in the IC and NBM modulate cholinergic transmission by opposing cortical activity required during taste memory formation and its retrieval. These findings support the hypothesis that $\mathrm{GABA}_{\mathrm{A}}$ receptors must be inactive during novel tasting to enable new memory formation, but must be active and inhibiting ACh release in the IC to allow memory retrieval. Divergence in ACh and GABA levels may produce differential alterations in excitatory and inhibitory neural processes within the cortex during acquisition and retrieval.

\section{References}

Acquas E, Wilson C, Fibiger HC (1996) Conditioned and unconditioned stimuli increase frontal cortical and hippocampal acetylcholine release: effects of novelty, habituation, and fear. J Neurosci 16:3089-3096. Medline

Akirav I (2007) NMDA Partial agonist reverses blocking of extinction of aversive memory by GABA(A) agonist in the amygdala. Neuropsychopharmacology 32:542-550. CrossRef Medline

Arroyo S, Bennett C, Aziz D, Brown SP, Hestrin S (2012) Prolonged disynaptic inhibition in the cortex mediated by slow, non-alpha7 nicotinic excitation of a specific subset of cortical interneurons. J Neurosci 32: 3859-3864. CrossRef Medline

Bahar A, Dudai Y, Ahissar E (2004) Neural signature of taste familiarity in the gustatory cortex of the freely behaving rat. J Neurophysiol 92: 3298-3308. CrossRef Medline

Berman DE, Hazvi S, Neduva V, Dudai Y (2000) The role of identified neurotransmitter systems in the response of insular cortex to unfamiliar taste: activation of ERK1-2 and formation of a memory trace. J Neurosci 20: 7017-7023. Medline

Bermúdez-Rattoni F (2004) Molecular mechanisms of taste-recognition memory. Nat Rev Neurosci 5:209-217. CrossRef Medline

Bures J, Bermúdez-Rattoni F, Yamamoto T (1998) Conditioned taste aversion: memory of a special kind. Oxford: OUP.

Capaldi ED, Hunter MJ, Privitera GJ (2004) Odor of taste stimuli in conditioned "taste" aversion learning. Behav Neurosci 118:1400-1408. CrossRef Medline

Casamenti F, Deffenu G, Abbamondi AL, Pepeu G (1986) Changes in cortical acetylcholine output induced by modulation of the nucleus basalis. Brain Res Bull 16:689-695. CrossRef Medline

Ceccarelli I, Casamenti F, Massafra C, Pepeu G, Scali C, Aloisi AM (1999) Effects of novelty and pain on behavior and hippocampal extracellular ACh levels in male and female rats. Brain Res 815:169-176. CrossRef Medline

Chu DC, Albin RL, Young AB, Penney JB (1990) Distribution and kinetics of GABAB binding sites in rat central nervous system: a quantitative autoradiographic study. Neuroscience 34:341-357. CrossRef Medline

Decker MW, McGaugh JL (1991) The role of interactions between the cholinergic system and other neuromodulatory systems in learning and memory. Synapse 7:151-168. CrossRef Medline

DeSousa NJ, Beninger RJ, Jhamandas K, Boegman RJ (1994) Stimulation of GABAB receptors in the basal forebrain selectively impairs working memory of rats in the double Y-maze. Brain Res 641:29-38. CrossRef Medline

Doron G, Rosenblum K (2010) c-Fos expression is elevated in GABAergic interneurons of the gustatory cortex following novel taste learning. Neurobiol Learn Mem 94:21-29. CrossRef Medline

Douchamps V, Jeewajee A, Blundell P, Burgess N, Lever C (2013) Evidence for encoding versus retrieval scheduling in the hippocampus by theta phase and acetylcholine. J Neurosci 33:8689-8704. CrossRef Medline

Dudchenko P, Sarter M (1991) GABAergic control of basal forebrain cholinergic neurons and memory. Behav Brain Res 42:33-41. CrossRef Medline

Everitt BJ, Robbins TW (1997) Central cholinergic systems and cognition. Annu Rev Psychol 48:649-684. CrossRef Medline

Ferreira G, Gutiérrez R, De La Cruz V, Bermúdez-Rattoni F (2002) Differential involvement of cortical muscarinic and NMDA receptors in shortand long-term taste aversion memory. Eur J Neurosci 16:1139-1145. CrossRef Medline

Ferreira MB, Da Silva RC, Medina JH, Izquierdo I (1992) Late posttraining memory processing by entorhinal cortex: involvement of NMDA and GABAergic receptors. Pharmacol Biochem Behav 41:767-771. CrossRef Medline

Freund TF, Gulyás AI (1991) GABAergic interneurons containing calbindin D28K or somatostatin are major targets of GABAergic basal forebrain afferents in the rat neocortex. J Comp Neurol 314:187-199. CrossRef Medline

Giorgetti M, Bacciottini L, Giovannini MG, Colivicchi MA, Goldfarb J, Blandina P (2000) Local GABAergic modulation of acetylcholine release from the cortex of freely moving rats. Eur J Neurosci 12:1941-1948. CrossRef Medline 
Giovannini MG, Ceccarelli I, Molinari B, Cecchi M, Goldfarb J, Blandina P (1998) Serotonergic modulation of acetylcholine release from cortex of freely moving rats. J Pharmacol Exp Ther 285:1219-1225. Medline

Giovannini MG, Rakovska A, Benton RS, Pazzagli M, Bianchi L, Pepeu G (2001) Effects of novelty and habituation on acetylcholine, GABA, and glutamate release from the frontal cortex and hippocampus of freely moving rats. Neuroscience 106:43-53. CrossRef Medline

Gutiérrez H, Gutiérrez R, Silva-Gandarias R, Estrada J, Miranda MI, Bermúdez-Rattoni F (1999) Differential effects of 192IgG-saporin and NMDA-induced lesions into the basal forebrain on cholinergic activity and taste aversion memory formation. Brain Res 834:136-141. CrossRef Medline

Gutiérrez R, Rodriguez-Ortiz CJ, De La Cruz V, Núñez-Jaramillo L, Bermúdez-Rattoni F (2003) Cholinergic dependence of taste memory formation: evidence of two distinct processes. Neurobiol Learn Mem 80: 323-331. CrossRef Medline

Guzmán-Ramos K, Osorio-Gómez D, Moreno-Castilla P, Bermúdez-Rattoni F (2010) Off-line concomitant release of dopamine and glutamate involvement in taste memory consolidation. J Neurochem 114:226-236. Medline

Hanamori T, Kunitake T, Kato K, Kannan H (1998) Responses of neurons in the insular cortex to gustatory, visceral, and nociceptive stimuli in rats. J Neurophysiol 79:2535-2545. Medline

Hasselmo ME (1999) Neuromodulation: acetylcholine and memory consolidation. Trends Cogn Sci 3:351-359. CrossRef Medline

Hasselmo ME (2006) The role of acetylcholine in learning and memory. Curr Opin Neurobiol 16:710-715. CrossRef Medline

Hasselmo ME, McGaughy J (2004) High acetylcholine levels set circuit dynamics for attention and encoding and low acetylcholine levels set dynamics for consolidation. Prog Brain Res 145:207-231. CrossRef Medline

Hasselmo ME, Schnell E (1994) Laminar selectivity of the cholinergic suppression of synaptic transmission in rat hippocampal region CA1: computational modeling and brain slice physiology. J Neurosci 14: 3898-3914. Medline

Hasselmo ME, Bodelón C, Wyble BP (2002) A proposed function for hippocampal theta rhythm: separate phases of encoding and retrieval enhance reversal of prior learning. Neural Comput 14:793-817. CrossRef Medline

Inglis FM, Day JC, Fibiger HC (1994) Enhanced acetylcholine release in hippocampus and cortex during the anticipation and consumption of a palatable meal. Neuroscience 62:1049-1056. CrossRef Medline

Khateb A, Fort P, Williams S, Serafin M, Mühlethaler M, Jones BE (1998) GABAergic input to cholinergic nucleus basalis neurons. Neuroscience 86:937-947. CrossRef Medline

Majchrzak M, Brailowsky S, Will B (1990) Chronic infusion of GABA and saline into the nucleus basalis magnocellularis of rats. II. Cognitive impairments. Behav Brain Res 37:45-56. CrossRef Medline

Markham CM, Luckett CA, Huhman KL (2012) The medial prefrontal cortex is both necessary and sufficient for the acquisition of conditioned defeat. Neuropharmacology 62:933-939. CrossRef Medline

Mechawar N, Cozzari C, Descarries L (2000) Cholinergic innervation in adult rat cerebral cortex: a quantitative immunocytochemical description. J Comp Neurol 428:305-318. CrossRef Medline

Mesulam MM, Mufson EJ, Levey AI, Wainer BH (1983) Cholinergic innervation of cortex by the basal forebrain: cytochemistry and cortical connections of the septal area, diagonal band nuclei, nucleus basalis (substantia innominata), and hypothalamus in the rhesus monkey. J Comp Neurol 214:170-197. CrossRef Medline

Miranda MI, Bermúdez-Rattoni F (1998) Acetylcholine determination of microdialysates of fetal neocortex grafts that induce recovery of learning. Brain Res Brain Res Protoc 2:215-222. CrossRef Medline

Miranda MI, Bermúdez-Rattoni F (1999) Reversible inactivation of the nucleus basalis magnocellularis induces disruption of cortical acetylcholine release and acquisition, but not retrieval, of aversive memories. Proc Natl Acad Sci U S A 96:6478-6482. CrossRef Medline

Miranda MI, Ramírez-Lugo L, Bermúdez-Rattoni F (2000) Cortical cholinergic activity is related to the novelty of the stimulus. Brain Res 882: 230-235. CrossRef Medline

Miranda MI, Ferreira G, Ramírez-Lugo L, Bermúdez-Rattoni F (2003) Role of cholinergic system on the construction of memories: taste memory encoding. Neurobiol Learn Mem 80:211-222. CrossRef Medline

Morón I, Ramírez-Lugo L, Ballesteros MA, Gutiérrez R, Miranda MI, Gallo M, Bermúdez-Rattoni F (2002) Differential effects of bicuculline and muscimol microinjections into the nucleus basalis magnocellularis in taste and place aversive memory formation. Behav Brain Res 134: 425-431. CrossRef Medline

Muir JL, Robbins TW, Everitt BJ (1992) Disruptive effects of muscimol infused into the basal forebrain on conditional discrimination and visual attention: differential interactions with cholinergic mechanisms. Psychopharmacology (Berl) 107:541-550. CrossRef Medline

Núñez-Jaramillo L, Ramírez-Lugo L, Herrera-Morales W, Miranda MI (2010) Taste memory formation: latest advances and challenges. Behav Brain Res 207:232-248. CrossRef Medline

Ogawa H, Hasegawa K, Otawa S, Ikeda I (1998) GABAergic inhibition and modifications of taste responses in the cortical taste area in rats. Neurosci Res 32:85-95. CrossRef Medline

Paxinos G, Watson C (1998) The rat brain in stereotaxic coordinates. San Diego: Academic.

Purón-Sierra L, Miranda MI (2014) Histaminergic modulation of cholinergic release from the nucleus basalis magnocellularis into insular cortex during taste aversive memory formation. PLoS One 9:e91120. CrossRef Medline

Rasmusson DD, Smith SA, Semba K (2007) Inactivation of prefrontal cortex abolishes cortical acetylcholine release evoked by sensory or sensory pathway stimulation in the rat. Neuroscience 149:232-241. CrossRef Medline

Rosenblum K, Berman DE, Hazvi S, Lamprecht R, Dudai Y (1997) NMDA receptor and the tyrosine phosphorylation of its $2 \mathrm{~B}$ subunit in taste learning in the rat insular cortex. J Neurosci 17:5129-5135. Medline

Sarter M, Bruno JP (1997) Cognitive functions of cortical acetylcholine: toward a unifying hypothesis. Brain Res Brain Res Rev 23:28-46. CrossRef Medline

Sarter M, Bruno JP (2002) The neglected constituent of the basal forebrain corticopetal projection system: GABAergic projections. Eur J Neurosci 15:1867-1873. CrossRef Medline

Weinberger NM, Bakin JS (1998) Learning-induced physiological memory in adult primary auditory cortex: receptive fields plasticity, model, and mechanisms. Audiol Neurootol 3:145-167. CrossRef Medline

Wood PL, Richard J (1982) GABAergic regulation of the substantia innominata-cortical cholinergic pathway. Neuropharmacology 21:969_ 972. CrossRef Medline

Woolf NJ, Eckenstein F, Butcher LL (1984) Cholinergic systems in the rat brain: I. projections to the limbic telencephalon. Brain Res Bull 13: 751-784. CrossRef Medline

Záborszky L, Heimer L, Eckenstein F, Leranth C (1986) GABAergic input to cholinergic forebrain neurons: an ultrastructural study using retrograde tracing of HRP and double immunolabeling. J Comp Neurol 250: 282-295. CrossRef Medline 